\title{
O universo onírico do Terpsí Teatro de Dança
}

\section{Resumo}

Este artigo propõe uma breve análise do espetáculo Ditos e Malditos: Desejos de Clausura do Terpsí Teatro de Dança, com a direção e a concepção de Carlota Albuquerque, buscando destacar aspectos da dança-teatro e de elementos plásticos encontrados nessa criação.

Palavras-chave: Terpsí Teatro de Dança; Coreografia; Elementos plásticos.

\begin{abstract}
This paper proposes a brief analysis of Ditos e Malditos: Desejos de Clausura (Told and Damned: Desires of Enclosure) from the Terpsí Dance Theatre Co., conceived and directed by Carlota Albuquerque, in the aim of highlighting dance theater aspects, besides some plastic elements found in it.
\end{abstract}

Keywords: Terpsí Teatro de Dança; Choreography; Plastic elements.

\section{Introdução}

Ditos e malditos: desejos de clausura, último trabalho do Terpsí Teatro de Dança, com a direção e a concepção de Carlota Albuquerque, é parte de um processo de criação com resultados múltiplos. Em seu material de divulgação, o grupo apresenta este projeto como um desejo de revelar as inquietudes sobre o amor, a solidão, o poder e a morte, perpassando por ideias e frases de escritores considerados malditos como Alfred Jarry, Augusto dos Anjos, Caio Fernando Abreu, Edgard Allan Poe e Samuel Beckett. Como ressalta Ferraz (2009), o espetáculo se propõe a retratar a ambiguidade de certos personagens, desvendada a partir do olhar do observador, como também a ambiguidade do próprio grupo, evidenciando o paradoxo entre o preservar e o destruir. Neste comentário, buscamos destacar alguns aspectos desta obra que são inerentes à tradição da dança-teatro, priorizando o enfoque sobre os elementos plásticos encontrados nessa criação, destacando como o jogo cênico estabelecido entre os corpos e

\footnotetext{
${ }_{1}^{1}$ Professora Adjunta na Universidade Federal do Rio Grande do Sul (UFRGS). Doutora em Estudos e Práticas Artísticas pela Université du Québec à Montreal (UQAM). Mestre em Ciências do Movimento Humano e Bacharel em Interpretação Teatral (UFRGS).
} 
os objetos revela um patrimônio imagético próprio ao grupo, revelando aspectos significativos de sua identidade.

\section{A filiação com a dança-teatro}

A companhia Terpsí Teatro de Dança, em sua trajetória de 22 anos de existência, sempre assumiu uma identificação com a dança-teatro (tanztheater $)^{2}$. Este termo apareceu na Alemanha no final dos anos 1920 e foi associado ao movimento conduzido por Rudolf Laban e Kurt Joss, que se opunha aos princípios coreográficos de Mary Wigman. Kurt Joss é o primeiro a utilizar o termo, em 1928, para designar uma companhia ao fundar o Tanztheater-Studio d'Essen. A companhia de Kurt Joss rapidamente obteve reconhecimento internacional e o termo rapidamente se difundiu ao apresentar um estilo específico, associando dança e dramaturgia teatral. Nos anos 1970, o termo reapareceu na Alemanha. Em 1973, ao assumir a direção do Teatro da Ópera de Wuppertal, Pina Baush $^{3}$ o rebatizou de Tanztheater de Wuppertal. Nos anos 1980, muitas companhias de dança na Alemanha se nomeavam tanztheater. Pina Baush é considerada o grande ícone da dança-teatro, reconhecida mundialmente pela sua renovação coreográfica. Segundo Moal (2008), suas criações contêm uma grande colagem de quadros oníricos intercalados a cenas de violência onde a utopia social se aproxima do drama psicológico. Sua poética influenciou não somente a dança contemporânea como também outras artes. Ciane Fernandes (2000) lista uma série de características que podem ser encontradas na obra da Pina Baush, as quais podemos entender como sendo aspectos fundamentais da dança-teatro. Entre eles, destacaremos certos elementos que também podem ser encontrados no espetáculo Ditos e Malditos: Desejos de Clausura, tais como: a relação entre expressão corporal e verbal; a relação entre o movimento corporal social (teatral) e abstrato (dança); a fragmentação no processo e no produto; a simultaneidade de eventos no palco; a alternância entre cenas em grupo e cenas solo. Essas características podem ser vislumbradas neste espetáculo e são o resultado de uma poética que vem sendo alimentada pelo grupo desde a sua criação. Também é importante destacar a colaboração que o grupo manteve por longo tempo com a bailarina gaúcha Eneida

\footnotetext{
2 Sobre tanztheater ver HOGHE, Raimund. Pina Bausch, histories d'un theatre dansé. Paris: L'Arche, 1987; SCHIMIDT, J. Tanztheater in Deutschland. Berlim: Propylaen Verlag, 1992; PEREIRA, Sayonara. Rastros do Tanztheater no Processo Criativo de ES-BOÇO. Campinas: Annablume, 1992.

${ }^{3}$ Sobre Pina Bausch ver SERVOS, Norbert. Pina Bausch, ou l'Art de dresser un poisson rouge. Paris: L'Arche, 2001; FERNANDES, Ciane. Pina Baush e o Wuppertal Dança-Teatro: repetição e transformação. São Paulo: Hucitec, 2000.
} 
Dreher (assessora técnica e artístisca), que por um certo período complementou seus estudos de dança na escola Folkwangschule de Essen. Além de Eneida Dreher, outras duas bailarinas, Sayonara Pereira e Simone Roratto ${ }^{4}$, também colaboraram com o grupo repassando partes de suas experiências artísticas desenvolvidas na Alemanha. Desse modo, através dessas colaborações, o Terpsí consolidou sua filiação com o tanztheater.

\section{Abrindo as portas do universo Terpsí: o jogo com grandes objetos, a força dos elementos plásticos e as imagens oníricas}

Quando o teatro é aberto ao público, encontramos um bailarino-ator, o experiente e versátil Raul Voges, que nos recebe na platéia proferindo fragmentos de textos literários mesclados a provébios populares. Os gestos dessa figura, que funciona como uma espécie de 'arauto', por vezes são literais, por exemplo, quando ele faz movimentos de lavar as mãos em baixo do foco de luz e diz "eu lavo minhas mãos". Na maioria das vezes, os gestos estão desconectados do significado da palavra, reforçando aspectos explorados pela dança-teatro. O clima de intimidade, sonho e delírio instaurado por este personagem já nos prepara para o que está por vir. Ao se retirar pouco a pouco da plateia, ele desaparece em um canto escuro do palco, atraindo o olhar do público. Só agora podemos perceber as grandes portas de ferro fechadas na nossa frente, como duas portas de um grande frigorífico ${ }^{5}$. Há também fios de arame farpado que separam o público da plateia, que estão em frente às portas do frigorífico, rente a primeira fila da plateia. Finalmente, com o olhar dirigido para a cena frontal, vemos uma mulher carregando uma grande lanterna, trazendo luz para as enormes portas cinzentas e frias. Ela caminha em direção ao meio das portas, próximo ao público. É a bailarina-atriz Ângela Spiazzi que ilumina a cena. Ela usa um vestido de cetim preto, com rendas brancas na bainha. É ela que, de costas para o público, abre as portas do frigorífico, no qual, durante o espetáculo, iremos ver imagens "descongelando" pouco a pouco, vindas da memória do Terpsí e também do espectador.

Ainda que o grupo trabalhe a partir de um material literário pré-estabelecido, a força das imagens do espetáculo reside, sobretudo, na composição do universo

\footnotetext{
${ }^{4}$ Eneida Dreher, Sayonara Pereira e Simone Rorato, em Porto Alegre, dançaram na Companhia Terra (19811984). A companhia Terra, além de apresentações no teatro, buscava popularizar a dança contemporânea com apresentações na rua, nos parques, nos presídios (DANTAS, Mônica, 1999).

${ }^{5}$ Essas portas grandes, aumentadas, lembram a grande porta do espetáculo Quem é? (1989), que também era colocada em certa proximidade com o público. De modo positivo, elas retornam neste espetáculo reforçando o universo onírico da coreógrafa Carlota Albuquerque. Essa prática de integrar grandes objetos em cena ou tranformá-los tem sido algo recorrente nos trabalhos do grupo, conferindo-Ihe uma certa identidade.
} 
onírico do grupo Terpsí. Mesmo que o que está sendo dito, venha de autores 'malditos' é, sobretudo, o repertório imagético do Terpsí que está em jogo. Grandes objetos em cenas, projeção de imagens, acessórios que são manipulados, apelo a fortes elementos plásticos ${ }^{6}$ e objetos de cenas imbricados ao movimento estão presentes de forma recorrente nos trabalhos do grupo. A riqueza do cenário, dos objetos e das imagens projetadas, enfim todos os elementos visuais do espetáculo oferecem ao espectador um ambiente de instalação visual resultado das experiências de seu processo de criação. É nesse sentido que a coreografia de Carlota Albuquerque não se detém somente na composição do movimento e desenhos de linhas no espaço, embora o faça com bastante precisão e qualidade. Grande parte da força do Terpsi e da aproximação com a dança-teatro se dá através de um certo ambiente de sonho, onírico, um desejo de pertencer ao caos das imagens da memória onde os elementos visuais são de grande importância. Nos rastros do tanztheater, não veremos uma história pronta (Pereira, 2010), no sentido de uma narrativa cênica nos moldes tradicionais, mas uma complexa sobreposição de imagens, pensamentos, sensações e memórias incorporadas e esboçadas no corpo dos bailarinos-atores.

Depois da abertura das portas do grande 'frigorífico' da memória, a imagem preponderante é a de uma grande cortina transparente de plástico. Ela conduz nossa atenção para o alto, onde vemos uma perna pendurada por trás da cortina. Novamente, a cena apresenta um elemento visual que reforça esse ambiente de sonho. Ângela abre a cortina e mais uma camada de memória é revelada. Vemos uma mulher deitada em uma cadeira de balanço. Ângela enrola a cortina e a retira do palco, ao mesmo tempo em que limpa o chão. Há sempre um grande número de ações cotidianas e simples desenvolvidas pela atriz-bailarina: iluminar, caminhar, carregar. Mais tarde, juntam-se a ela as bailarinas-atrizes Gabriela Peixoto e Francine Pressi. As três mulheres são visualmente semelhantes, elas usam vestidos pretos rendados. Elas dançam em torno de uma bacia e um balde com água. Objetos cênicos que já foram bastante explorados em espetáculos do Terpsí, como por exemplo, Banho (2001). Formando um semi-círculo, elas lavam repetidamente as mãos, lembrando de um ritual de purificação. Em determinados momentos, esses movimentos cotidianos são entrecortados por uma certa estilização de movimento. Braços alongados cruzam e

\footnotetext{
${ }^{6}$ Fortes elementos plásticos mesclados aos movimentos coreográficos fizeram parte de muitas coreografias da dança-teatro, como exemplos de repercussão internacional temos: a mesa como objeto principal da coreografia Mesa Verde (1932) de Kurt Joss e a banheira na coreografia denominada Na Banheira (1980) de Susanne Linke.
} 
se estendem frente ao corpo, em movimentos rápidos e ágeis. Em poucos segundos, vemos a qualidade, a precisão e a experiência de movimento das intérpretes. Novamente aqui uma matriz da filiação com a dança-teatro onde não há hierarquia entre gesto estilizado e certas ações funcionais, cotidianas. Caem do céu folhas de papel, onde vemos cópias em preto e branco de rostos, são as fotos dos autores malditos. Duas mulheres dançam em meio a essas folhas, elas também juntam os papéis pelo chão e colocam as fotos em frente ao rosto. A coreografia está sempre se aproximando de certos objetos, sejam objetos que tem mais concretude como a cadeira, as bacias e os baldes, sejam as folhas de papel que perpassam o corpo, ou ainda pequenos objetos que são manipulados rapidamente (como o isqueiro, por exemplo). Os bailarinos formam um círculo e dançam livremente uma ciranda sobre papéis dispersos e jogados no chão. Novamente, o ‘arauto’ aparece e canta um pequeno trecho da canção La vie en rose. Ele recita frases desconexas vestindo um avental de açougueiro. Ele realiza um pequeno solo. Três mulheres o cercam, uma delas fuma um cachimbo. Todas essas cenas citadas não indicam um tempo histórico nem uma situação dramática especifica, elas pertencem a um tempo onírico da poesia, no qual a dança-teatro convida o espectador a participar (Servos, 2001).

Em um dos melhores momentos do espetáculo, uma mulher desce uma escada branca que vemos ao fundo do palco. Ela veste um terno, calça e camisa e realiza movimentos fortes e vigorosos. Ela tem nas mãos dois serrotes. Ao aproximar-se do público, identificamos a bailarina-atriz Suzana Schoellkopf. Como um morcego, ela balança o serrote como asas, as lâminas do serrote cruzam em frente ao seu corpo. Ouvimos os barulhos dos serrotes que batem no chão. Ela cambaleia pelo palco, rola no chão, sempre com os serrotes na mão. Ela gira alucinadamente e bate os serrotes em partes do corpo, desvairada. Entrelaça os serrotes e dança balançando os quadris, há uma certa sensualidade no movimento. Antes de desaparecer pela escada, ela se aproxima do palco e bate os serrotes nos arames farpados rente ao público. Encarnando uma figura sensual e de certa forma diabólica, ela é a representação feminina mais impactante que encontramos em cena. Há uma certa violência em seus movimentos. Esta cena exemplifica como a coreógrafa Carlota Albuquerque domina o uso dos objetos associados à coreografia. Às vezes, esquecemos que a bailarina manipula dois serrotes. O movimento de braços dá continuidade ao movimento do serrotes, como se fossem longos braços, num verdadeiro entrelaçamento entre objeto e movimento. 
Outro momento significativo acontece quando cenas simultâneas tomam conta do palco: corpos que correm, diferentes manipulações com água e fogo. Dois bailarinos dançam sensualmente, uma mulher fuma um charuto, outra rola pela escada, uma mulher cospe no rosto do 'arauto.' Em meio ao conjunto de ações, um casal dança em cima de uma mesa, num instigante jogo cênico entre homem e mulher. Por baixo e em cima da mesa, seguem-se os movimentos de um dueto coreografado compondo com a mesa que por vezes os separa. Em meio a outras movimentações o casal toma conta da atenção do público e se dirige ao centro da cena. Ele a segura por cima do ombro. Eles dançam próximos e ele a lança no espaço. Rolamentos ao chão, seus corpos se entrecruzam, ora no chão, ora em pé. As cenas de modo geral são curtas, esboçadas, quase não há pausas. A mesa retorna uma segunda vez, agora ao centro do palco. Ouvimos um som de vento e, nesse momento, todos os bailarinos-atores encontram-se no palco. Além da mesa ter sido bastante explorada pelo casal, ela também serve de apoio para uma movimentação do grande grupo. Novamente, esse grande objeto se desloca com fluidez pela cena, ele serve tanto para o dueto quanto para o grande grupo. Há uma liberdade na utilização dessa mesa. Às vezes, os objetos são utilizados de um modo mais funcional, já em outras são utilizados de modo mais livre, onde os bailarinos compõem seus corpos em relação ao objeto, ou o objeto manipulado por algum bailarino-ator compõe com o corpo do outro.

No final do espetáculo, há um solo de Ângela Spiazzi em uma cadeira de balanço, a mesma cadeira estilizada que vimos no começo do espetáculo. A bailarina acompanha o balanço da cadeira, mimetizando seu movimento. Ao som de uma valsa, suas pernas se entrecruzam entre chassés e entrelacés. Subindo em cima dos braços da cadeira, ela se equilibra, grandes braços abertos e arrisca jogar o peito para trás. Ela está no centro da cena e essa figura tem uma forte presença cênica. Nos últimos instantes da coreografia, ela se equilibra novamente na mesma cadeira de balanço, porém, agora vemos o seu corpo em perfil, altivo. Ela parece que está em cima de um barco. Alguém Ihe alcança os serrotes, um em cada mão. Papéis caem do céu e atravessam o palco. Sustentando o corpo em perfil, ela abre e fecha os braços como um morcego. As portas do frigorífico se fecham. Nos espetáculos do Terpsí, as mulheres, de modo geral, são figuras fortes. A última figura que vemos é o corpo forte desta mulher que se equilibra em uma cadeira. Oposto da vulnerabilidade, ela se mantém firme, apesar da instabilidade onde pisa. Resta aí, talvez, um desafio para o Terpsí, 
investir mais na vulnerabilidade do discurso corporal. Se há propositalmente um certo caos em cena, como repassá-lo ao corpo? Como oscilar mais a balança em direção aos limites, à fragilidade e às maldições do corpo?

Antonin Artaud é um dos autores cujas fotos podemos ver, penduradas entre os arames farpados. Ninguém melhor que Artaud, para compreender o corpo na sua dimensão maldita, doentia e limitada. Ao transpor um certo caos que há em cena para o corpo, é possível estabelecer uma ligação com a noção de "corpo sem órgãos" (CsO)7, proposta por Gilles Deleuze e Felix Guattari (1980). Estes autores propõem uma definição intensa de corpo em termos de forças potenciais do ser, em oposição às formas estabelecidas, constituídas. Deleuze toma emprestada de Antonin Artaud a expressão (CsO), a qual exprime o lado esquizofrênico do poeta, o lado sombrio, aquela dimensão que se recusa a pensar um corpo reduzido a uma hierarquia soberana dos órgãos (SILVA, 2010). Trata-se de valorizar a arte enquanto captura de forças e não representação de formas obtidas. Para Deleuze e Gattarri (1980), trata-se de valorizar a arte como ato, como devir de uma realidade. Nesse sentido, em termos de discurso do corpo, a fim de equilibrar mais os versos malditos com uma atuação "maldita”, talvez o Terpsí, nesse espetáculo, pudesse penetrar mais em zonas de exploração de movimentos imprevistos e esboçados, de vibrações de vozes inesperadas, estados alterados do corpo, etc., como na cena em que vemos a mulher descendo as escadas e dançando com os serrotes nas mãos, de modo quase desnorteado. O corpo em sua dimensão não somente de devaneio e insensatez, na qual o espetáculo apresenta de modo bastante convincente, mas também em termos de pesadelo e de obscuridade.

\section{Fechando as portas}

Os paradoxos entre sonhar e despertar, lavar e sujar, poesia e clichê, coreografia e caos, movimentos estilizados e movimentos cotidianos, gritos e vozes são revelados através da livre inspiração em certos autores no espetáculo Ditos e malditos: desejos de clausura. Os elementos plásticos, com os quais a coreógrafa Carlota Albuquerque trabalha são integrados aos movimentos dos bailarinos-atores, de forma rica e elaborada. Estes elementos brotam de todos os cantos: cadeiras que se transformam,

\footnotetext{
7 O CsO, de acordo com Gilles Deleuze e Felix Guattari, (1980) tem o ovo como modelo. Este modelo expõe a vitalidade inorgânica do tecido não ainda estabilizado sob a forma de organismo. Esta concepção requer uma crítica política das noções de organismo, de organização, de poder centralizado, finalmente de hierarquia em relação aos órgãos do corpo. No caso da dança, também é possível encontrar aspectos do corpo fortemente hierarquizados, sobretudo no que se refere às técnicas corporais. Sobre o CsO ver Sauvagnargues (2006).
} 
uma perna pendurada ao teto, papéis que caem, grandes portas, escadas, mesas, panos, cortinas, bacias, baldes, charuto, lanterna, lente de aumento, etc, revelando a inventividade da coreógrafa Carlota Albuquerque e reforçando sua mise en scène onírica. Os excelentes bailarinos-atores do grupo estão abertos a diferentes camadas da percepção, jogando com estes diferentes objetos de cena e suas múltiplas dimensões e usos. Há também uma boa percepção do grupo em relação às imagens projetadas e seus deslocamentos em termos de espaço. Nesse espetáculo, a companhia Terpsí Teatro de Dança, em uma atmosfera de sonho e insensatez, inspirado por autores malditos, revive seu patrimônio de imagens poéticas demonstrando uma forte identificação com o universo onírico da dança-teatro. O investimento em diferentes objetos, alguns já utilizados em trabalhos anteriores, reforça, de modo positivo, um certo 'universo Terpsí' onde há uma confluência de elementos plásticos e visuais em sintonia com a coreografia.

\section{Referências}

CORVIN, Michel. Dictionnaire encyclopédique du théâtre. Paris : Larousse, 18894 p., 2003 DANTAS, Mônica. Dança: O enigma do movimento. Porto Alegre: Ed. Universidade/UFRGS, 1999.

DELEUZE, Gilles; GUATTARI, Félix. Capitalisme et schizophrénie: mille plateaux. Paris: Éditions de Minuit, 1980.

FERRAZ, Wagner. Ditos e malditos: desejos da clausura - Processo de criação da Terpsí Teatro de Dança. Porto Alegre, 2009.

FERNANDES, Ciane. Pina Baush e o Wuppertal Dança-Teatro: repetição e transformação. São Paulo: Hucitec, 2000.

MOAL, Philippe Le (org.). Dictionnaire de la danse. Paris: Éditions Larousse, 2008.

PEREIRA, Sayonara. Rastros do Tanztheater no Processo Criativo de ES-BOÇO. Campinas: Annablume, 1992.

SAUVAGNARGUES, Anne. "Corps sans organes.»In: Dictionnaire du corps. Paris: Presses Universitaires de France, 2007.

SERVOS, Norbert. Pina Bausch, ou l'Art de dresser un poisson rouge. Paris: L'Arche, 2001.

SILVA, Suzane Weber. "Les pratiques du danseur-créateur vis-à-vis des pratiques dominantes en danse contemporaine : trois études de cas". Tese de Doutorado. Montréal: Université du Québec à Montréal (UQAM), Janeiro, 2010. 